\title{
Feeding a Family in a Recession: Food Insecurity Among Minnesota Parents
}

\author{
Meg Bruening, RD, MPH, Richard MacLehose, PhD, Katie Loth, RD, MPH, Mary Story, RD, \\ PhD, and Dianne Neumark-Sztainer, RD, PhD, MPH \\ Division of Epidemiology and Community Health, School of Public Health, University of \\ Minnesota, Minneapolis, MN
}

\begin{abstract}
Objectives-We assessed current levels of food insecurity among a large, diverse sample of parents and examined associations between food insecurity and parental weight status, eating patterns, and the home food environment.

Methods-Project F-EAT (Families and Eating and Activity Among Teens) examined the home food environments of adolescents. Parents and caregivers $(n=2095)$ living with adolescents from the Minneapolis-St. Paul, Minnesota school districts completed mailed surveys during a 12-month period in 2009-2010. We performed our assessments using multivariate regressions.
\end{abstract}

Results-Almost 39\% of the parents and caregivers experienced household food insecurity, whereas $13 \%$ experienced very low food security. Food insecurity was significantly associated with poorer nutrition-related variables such as higher rates of parental overweight and obesity, less healthy foods served at meals, and higher rates of binge eating. Food-insecure parents were 2 to 4 times more likely to report barriers to accessing fruits and vegetables.

Conclusions-Food insecurity was highly prevalent. Environmental interventions are needed to protect vulnerable families against food insecurity and to improve access to affordable, healthy foods.

The United States is experiencing the most severe economic collapse since the Great Depression. ${ }^{1,2}$ By historical standards, unemployment levels remain extremely high ${ }^{3}$; lowincome families, who have been disproportionately burdened by the recession, are struggling to make ends meet. ${ }^{4,5}$ This financial struggle often results in increased levels of food insecurity - the lack of consistent access to healthy, affordable food. ${ }^{1}$ Current national estimates suggest $16 \%$ of US adults and $25 \%$ of US children are food insecure. ${ }^{1,6}$

Common household responses to having inadequate resources for food include food budget adjustments, reduced food intake, and alterations in types of food purchased. Nutrient-dense

Correspondence should be sent to Meg Bruening, 1300 South Second Street, Suite 300, Minneapolis, MN, 55454 (brue0123@umn.edu).

Reprints can be ordered at http://www.ajph.org by clicking the "Reprints/ Eprints" link.

\section{Contributors}

M. Bruening conceptualized the study and took the lead in the analysis and in writing the article. R. MacLehose supervised and assisted in the analysis and reviewed the article. K. Loth assisted in the study design and in writing the article. M. Story assisted in the study design and in writing the article. D. Neumark-Sztainer supervised the study and assisted in the study design and in writing the article.

Note. The contents of this presentation are the sole responsibility of the authors and do not necessarily represent the official views of the National Heart, Lung, and Blood Institute, the National Institutes of Health, or the Centers for Disease Control and Prevention.

Human Participant Protection

The University of Minnesota's institutional review board human subjects committee approved all protocols. 
foods (e.g., fruits, vegetables, whole grains, and lean meats) are significantly more expensive per calorie than are energy-dense foods (e.g., soft drinks, salty and sugary snacks, and pastries). ${ }^{7,8}$ Thus, studies have shown that in households experiencing food insecurity, food variety tends to decrease and the consumption of energy-dense foods tends to increase. ${ }^{9}$ A study in Minnesota found that food-insecure youths were more likely to eat fast food and less likely to consume breakfast and family meals than were food-secure youths. ${ }^{10}$ Poor dietary intake resulting from household food insecurity has been associated with numerous health problems, such as higher rates of diabetes, stress and depression, and hospitalization. ${ }^{11-15}$ Although the literature is inconsistent, ${ }^{16}$ food-insecure households, particularly those headed by single mothers, have been found to have higher rates of overweight and obesity. ${ }^{17-19}$ The concurrent prevalence of obesity and food insecurity is often referred to as the hunger-obesity paradox. ${ }^{20,21}$

Households with children are more likely to be food insecure than are households without children. ${ }^{19,22}$ Studies have shown that parents, especially mothers, tend to restrict their own intake so enough food will be available for their children. ${ }^{23,24}$ Additionally, communities of color and immigrant communities experience significantly higher rates of food insecurity compared with the national average. ${ }^{25-27}$

Given the shifts in the economic well-being of the United States, we assessed the current prevalence of food insecurity across sociodemographic characteristics among parents in a large, ethnically diverse population in Minnesota. To better describe implications of current food insecurity among parents, we also examined associations between food insecurity and parental weight status and eating patterns as well as measures of the home food environment.

\section{METHODS}

We drew our data from Project F-EAT (Families and Eating and Activity Among Teens), a population-based study of parents of adolescents aimed at learning more about food, physical activity, and home environments. A sample of 3709 parents or guardians of the adolescents enrolled in EAT (Eating and Activity in Teens) 2010 completed Project F-EAT surveys. EAT 2010 is a multilevel investigation of eating, physical activity, and weightrelated topics among a diverse sample of 2793 adolescents from the Minneapolis-St. Paul, Minnesota school districts. Adolescents participating in EAT 2010 provided contact information for up to 2 parents or guardians; approximately $30 \%$ provided contact information for 1 parent or guardian, and $70 \%$ provided information for 2 parents or guardians. Project F-EAT mailed 4777 surveys to parents or guardians of adolescents, and $3709(77.6 \%)$ parents responded. Parental response rates did not differ by adolescent gender, age, socioeconomic status, or language spoken at home, but rates did differ by race/ethnicity with the highest response rates among the parents of White adolescents. Parental response rates were $92.4 \%$ if the adolescent was White, $82.4 \%$ if African American, $85.8 \%$ if Hispanic, $85.8 \%$ if Asian American, $74.5 \%$ if Native American, and $82.8 \%$ if mixed or other. Overall, the response rate among parents was high: at least 1 parent responded for $85.3 \%(n=2382)$ of the adolescents, and for $67.9 \%(n=1327)$ of the adolescents who provided information on 2 parents, both parents responded. Because food insecurity has been previously shown to have a particularly adverse effect in households with children, ${ }^{19,22}$ we included only parents who reported that they live with their adolescents. Thus, the analytic sample involved 2095 respondents.

Parents completed surveys by mail or telephone interview. To meet the needs of this culturally diverse group of parents, the survey was available in English, Spanish, Hmong, and Somali; additionally, we offered the telephone interview in East African and Hmong 
dialects of Oromo, Amharic, and Karen. Each parent received a \$25 gift card for her or his participation. A subsample of 102 parents completed the Project F-EAT survey twice in a 2week period to examine test-retest reliability of survey questions. The Wilder Research Foundation in St. Paul, Minnesota (http://www.wilder.org) performed the data collection, which ran from October 2009 to October 2010.

\section{Measures}

Food insecurity - We assessed food security using the previously validated US Household Food Security Survey Module modified for self-administration, ${ }^{28,29}$ which measures food security over the past 12 months. The survey module includes the following items: "Is this statement true?: 'The food that we bought just didn't last, and we didn't have money to get more",; "Is this statement true?: 'We couldn't afford to eat balanced meals"'; "In the past 12 months, did you or other adults in your household ever cut the size of your meals or skip meals because there wasn't enough money for food?"; "In the past 12 months, did you ever eat less than you felt you should because there wasn't enough money for food?"; and "In the past 12 months, were you ever hungry but didn't eat because there was not enough money for food?" If participants responded "often true," "sometimes true," or "yes" to more than 2 questions, then we categorized parents as food insecure; otherwise, we classified parents as food secure. As in previous studies, we considered families to have very low food security if they gave 5 or more affirmative responses to the screener. ${ }^{29}$

Sociodemographics-Self-report determined sociodemographic characteristics, including age, gender, race/ethnicity, marital status, educational attainment, and participation in public assistance. The following question measured race/ethnicity: "Do you think of yourself as White; Black or African American; Hispanic or Latino; Asian American; Native Hawaiian or Pacific Islander; American Indian or Native American; or other?" Because of limited numbers in some racial/ethnic groups, we recoded race/ethnicity into White, African American, Latino, Asian American, and other. One question assessed current marital status. Participants could select 1 option from the following: "married or in a committed relationship"; "divorced or separated"; or "single, widowed, or other." We recoded marital status as married or single. Two questions measured household educational attainment: "What is the highest grade or year of school that you have completed?" (testretest $r=0.84$ ) and "What is the highest grade or year of school that your spouse or partner has completed?" (test-retest $r=0.75$ ). For analyses, household educational attainment included 4 categories: "did not finish high school," "finished high school," "finished college," and "advanced degree." Participants reported on employment status through the following question: "Which of the following best describes your current work situation?" (test-retest $r=0.82$ ). Five options were available: "working full time," "working part time," "stay at home caregiver," "currently unemployed but actively seeking work," and "not working for pay." Participants reported on household income level through the following question: "What was the total income of your household before taxes in the past year?" (test-retest $r=0.94$ ). Income included 6 categories ranging from less than $\$ 20,000$ to $\$ 75,000$ or more.

Weight status-Participants' self-reports of height and weight resulted in calculated body mass index (BMI; defined as weight in kilograms divided by the square of height in meters). For analyses, we assessed BMI as a continuous variable and dichotomized it according to BMI cutpoint guidelines for adults ${ }^{30}$ : overweight (BMI 25) and obese (BMI 230 ).

Eating patterns-The following question measured breakfast consumption (as a continuous variable): "During the past week, how many days did you eat breakfast?" (testretest $r=0.82$ ). Participants selected 1 of 7 responses ranging from never to every day 
(range: 0-7). Participants reported on fruit and vegetable consumption with 2 items: "Thinking back over the past week, how many servings of fruits (vegetables) did you usually eat on a typical day?" (range: 0-7; test-retest fruits $r=0.69$; test-retest vegetables $r$ $=0.57$ ). To help participants better understand serving sizes, we provided participants cues such as, "A serving is a half cup of fruit or $100 \%$ fruit juice or a medium piece of fruit." We summed fruits and vegetables for analyses. One item measured sugar-sweetened beverage consumption: "Thinking back over the past week, how often did you drink sugar-sweetened beverages (regular soda pop or Kool-Aid)?" (test-retest $r=0.66$ ). Response options ranged from less than once per week to more than twice per day (range: 0-6). The following question assessed fast food consumption: "In the past week, how often did you eat something from a fast food restaurant, such as McDonald's, Burger King, Domino's, or similar places?" (test-retest $r=0.55$ ). Response options ranged from never to more than 7 times (range: 0-6). One question examined binge eating: "In the past year, have you ever eaten so much food in a short period of time that you would be embarrassed if others saw you (binge eating)?" (test-retest $r=0.95) .{ }^{31}$

Home food environment-Participants reported on family meal frequency with 1 item: "During the past week, how many times did all, or most, of your family living in your household eat a meal together?" (range: never to more than 7 times; test-retest $r=0.72$ ). Six items measured the types of food served at family meals: "Think about a typical family dinner at your home. Is a green salad served? Are vegetables other than potatoes served? Is $100 \%$ fruit juice served? Is fruit (not including juice) served? Is milk served? Are sugarsweetened beverages (soda pop, Kool-Aid, etc.) served?" (individual item test-retest $r$ values ranged from 0.56 to 0.85$).{ }^{32}$ Response options ranged from never to always on a 4 point Likert scale and we recoded these as sometimes or rarely and usually or always. Parents also reported on time spent preparing meals with an open-ended question: "How many hours per week do you normally spend preparing food for your family?" (test-retest $r=0.68) .{ }^{33}$ Four items adapted from Campbell et al. assessed perception of fruit and vegetable access, addressing cost, variety, and quality of produce, with response options ranging from strongly disagree to strongly agree (individual item test-retest $r$ values ranged from 0.38 to 0.56$).{ }^{34} \mathrm{We}$ categorized response options to agree or disagree.

\section{Statistical Analysis}

We calculated descriptive statistics for demographic and other key variables. We assessed associations between food insecurity and key sociodemographic variables using the $t$ test or the $\chi^{2}$ test, as appropriate. We then examined crude (unadjusted) associations between food insecurity as the independent variable and parental weight status, parental eating patterns, and the home food environment as dependent variables. We estimated adjusted associations using multiple regressions, adjusting all regression models for age, gender, race/ethnicity, marital status, employment status, and highest household education. Using linear regression, we modeled continuous dependent variables (BMI, breakfast consumption, servings of fruits and vegetables, sugar-sweetened beverage consumption, fast food consumption, family meal frequency, fast food at family meal frequency, and time spent preparing meals). Logistic regression models allowed us to estimate the association between food insecurity and dichotomous dependent variables (overweight and obesity status, binge eating, variables related to the foods served at family meals, and variables related to perceived fruit and vegetable access). After estimating the regression models, we computed predicted probabilities for each observation in the data set at the observed value of the confounder variables. We have reported the average of these predicted values as the adjusted mean (which can be viewed as a generalization of standardization to the total study population). Finally, we calculated differences between the adjusted proportions with confidence 
intervals (CIs) and $P$ values, which we estimated using bootstrapping, a resampling method. ${ }^{35}$ We ran all analyses using Stata version 10.0 (StataCorp LP, College Station, TX).

\section{RESULTS}

Food insecurity and very low food security were prevalent among Project F-EAT parents: $38.9 \%$ of respondents reported food insecurity, and $13.3 \%$ reported very low food security. Food-insecure parents were slightly younger than were food-secure parents (mean age $=40.3$ \pm 7.6 and $42.1 \pm 8.1$ years, respectively; $P<.01$ ). Women, Asians and other non-White racial groups, and single parents had the highest rates of food insecurity (Table 1). There were significant inverse relationships between income and education and food insecurity status: those parents reporting lower income and educational attainment were more likely to report being food insecure.

Food-insecure and -secure parents differed in BMI and eating patterns. Unadjusted results (Table 2) and results adjusted for sociodemographic factors (Table 3) were similar; thus, we have discussed adjusted results. There were significant differences in overweight status between the food-secure and -insecure parents, with more food-insecure parents than foodsecure parents being overweight. Food-insecure parents reported poorer eating behaviors than did food-secure parents for all behaviors examined. For example, food-insecure parents ate breakfast less frequently, consumed almost an additional full serving of sugar-sweetened beverages each day, and were more likely to report binge eating.

In general, the home food environment was poorer in food-insecure households than in food-secure households. Food-insecure parents more often reported having fast food at family meals and serving sugar-sweetened beverages at family meals, and food-insecure parents reported serving healthy items such as green salad, vegetables, and fruit less often than did food-secure parents. For example, $22.0 \%$ of food-secure parents reported serving sugar-sweetened beverages at family meals on a regular basis, as compared with $15.7 \%$ of food-secure parents, for an adjusted difference of $6.4 \%(95 \% \mathrm{CI}=2.5,10.3)$. Finally, there were large differences in perceived access to fruits and vegetables between food-secure and food-insecure parents. For example, $39.8 \%$ of food-insecure parents reported that fruits were too expensive to purchase compared with only $13.6 \%$ percent of food-secure parents, for an adjusted difference of $26.2 \%$ (95\% CI=21.5, 30.6).

\section{DISCUSSION}

More than one third (39\%) of the parents in the Project F-EAT sample were food insecure, including 13\% who reported very low food security. Households in which the primary custodial parent was from an ethnic minority group or had lower levels of education were at the greatest risk for food insecurity. Food insecurity was associated with poorer nutritionrelated outcomes, including increased rates of overweight and obesity, higher rates of binge eating, less reported access to fruits and vegetables, and poorer quality of foods served at family meals. These findings highlight the urgent need for addressing the high prevalence of food insecurity, particularly among parents of adolescents and among parents from ethnic minority groups with low levels of education.

In 2009, the statewide rate of food insecurity in Minnesota was 10.5\%, whereas the US rate of food insecurity was $14.7 \%$. (Note that these percentages using the 18 -item US Department of Agriculture food security questionnaire. $\left.{ }^{1,6}\right)$ The parents and guardians sampled in Project F-EAT reported food insecurity levels that were almost 4 times state averages and more than 2.5 times the national average. Very low food security was twice that of state and national averages. Although Project F-EAT targeted a diverse, urban 
population, we were dismayed to find that 2 in 5 parents in our sample were dealing with food scarcity. The current sample included a large portion of single mothers, a population shown to carry an inordinate burden of food insecurity worldwide. ${ }^{23,24,36-38}$ Single mothers are more likely to have less education and to have lower incomes than are other parents, often resulting in higher rates of food insecurity, 39,40 which our results support. The effects of food insecurity, particularly on households headed by women, were related to most of the nutrition-related outcomes we assessed.

The results in our study uphold the previously observed paradox between food insecurity and overweight and obesity. ${ }^{20,21,41}$ Food-insecure parents were significantly more likely to be overweight or obese. In addition, food-insecure parents were more likely to serve unhealthy foods, such as sugar-sweetened beverages and less likely to serve fruits and vegetables at family meals. Food-insecure parents consumed breakfast less often, consumed fewer servings of fruits and vegetables and more sugar-sweetened beverages and fast food. As mentioned previously, calories tend to be less expensive for unhealthy, calorie-laden foods ${ }^{8}$; thus, food-insecure households may be making less healthful decisions to make their food dollar stretch. ${ }^{9}$ Our findings support the idea that food-insecure households struggle with healthy eating much more regularly than do food-secure households.

The higher weight status and poorer eating patterns of food-insecure parents may be partially related to the fact that food-insecure parents reported much more difficulty in accessing healthy foods such as fruits and vegetables than did food-secure parents. Foodinsecure parents in our sample were 3 to 4 times more likely to find fruits and vegetables to be too expensive to purchase. In addition, food-insecure parents reported that the quality and variety of available fruits and vegetables were poor. Research has shown that low-income families often do their daily shopping at small corner stores or convenience stores in their neighborhoods. ${ }^{41}$ Food at corner stores and convenience stores can be $150 \%$ to $400 \%$ higher in price than is food at a typical supermarket because these vendors often do not have the purchasing power or equipment to make nutrient-dense food more affordable or appealing. ${ }^{42-46}$ Demonstration projects in-centivizing the purchase of fruits and vegetables by providing coupons among participants in the Supplemental Nutrition Assistance Program (SNAP) have been found to be successful. ${ }^{47}$ Food-insecure parents in Project F-EAT would likely benefit from an expansion of fruit and vegetable incentive programs.

We found that food-insecure adults were at nearly twice the risk for binge eating than were food-secure adults. A recent Food and Nutrition Service report on redemption patterns of SNAP allotment showed that by 2 weeks after receiving their SNAP allotment, families already had less than one quarter of their monthly food allotment remaining. ${ }^{48}$ Olson et al. have documented a cycle of deprivation and overeating among food-insecure parents: when a family is able to obtain food, overconsumption at the influx of food occurs; when there is not enough food, parents, especially mothers, tend to restrict their intake. ${ }^{49}$ This cycle can promote the storage of fat and create an unhealthy relationship with food. ${ }^{49}$ The high prevalence of both binge eating and obesity among food-insecure respondents in our study provides partial support for this theory and indicates a need for further exploration of pathways of association.

\section{Strengths and Limitations}

Study strengths and limitations should be taken into account in interpreting the findings. Our use of a large and diverse sample from a large metropolitan area is a study strength. Minneapolis-St. Paul has large communities of Hmong and Somali, who were included in the sample, providing an opportunity to learn about these population groups. However, because we included only parents in the Minneapolis-St. Paul area, the generalizability of study findings beyond this area may be limited. The wide breadth of the parental variables 
assessed in our study is another important strength; for example, we are unaware of other large population-based studies that have examined the association between binge eating and food insecurity. We used a strong, commonly used screening tool to assess food security, although the precision of this measurement might fall short of what we would have obtained using the full questionnaire. ${ }^{50}$ In interpreting the findings, it is important to note that measures used to assess parent weight status and eating patterns were brief and derived from self-reports. Finally, as a cross-sectional study, we could only examine associations and cannot draw inferences about temporality or causality of relationships between variables.

\section{Conclusions}

There is an ongoing need to eliminate food insecurity among households in the United States. The data indicated that amid the current economic conditions, food-insecure parents are at greater risk for obesity and poorer nutritional outcomes than are food-secure parents. Future studies should investigate mediating factors, such as the role that stress, financial and otherwise, plays in household food insecurity and its effects. Additional research is needed to examine the effects that high rates of household food insecurity have on the health and well-being of children and adolescents.

Despite the need for more research, our findings indicate that we need to mobilize now to help vulnerable families. Public assistance programs exist to decrease the burden of food insecurity; however, more work is needed to improve access to healthy foods. Many families may benefit from an expansion of fruit and vegetable incentive programs and improved access to healthy foods in their neighborhood. In addition, programs may want to target single mothers to improve their education level and income to decrease their risk for food insecurity and other poverty-related problems.

\section{Acknowledgments}

This project was supported by Project F-EAT via an award (R01HL093247) from the National Heart, Lung, and Blood Institute (to D. N.-S.) and by the Adolescent Health Protection Research Training Program of the Centers for Disease Control and Prevention (grant T01-DP000112 to M.B.).

We would like to thank the parents and caregivers who took the time to participate in Project F-EAT and Wilder Research Foundation for assistance in data collection.

\section{References}

1. Nord, M.; Coleman-Jensen, A.; Andrews, M.; Carlson, S. Household Food Security in the United States, 2009. Washington, DC: US Department of Agriculture, Economic Research Service; Nov. 2010

2. Hipple, SF. Monthly Labor Review. Bureau of Labor Statistics; The Labor Market in 2009: Recession Drags On. Available at: http://www.bls.gov/opub/mlr/2010/03/art1full.pdf

3. US Bureau of Labor Statistics. [Accessed May 12, 2011] The Employment Situation. Apr. 2011 Available at: http://www.bls.gov/news.release/archives/empsit_05062011.pdf

4. US Bureau of Labor Statistics. [Accessed May 12, 2011] A Profile of the Working Poor. 2009. Available at: http://www.bls.gov/cps/cpswp2009.pdf

5. US Census Bureau. [Accessed May 12, 2011] Income, Poverty and Health Insurance in the United States. 2009. Available at: http://www.census.gov/prod/2010pubs/p60-238.pdf

6. Food Research Action Center. [Accessed May 12, 2011] State by State Date on Food Insecurity. Available at: http://frac.org/wp-content/uploads/2010/11/food_insecurity_by_state_2007-2009.pdf

7. Monsivais P, Drewnowski A. The rising cost of low-energy-density foods. J Am Diet Assoc. 2007; 107 (12):2071-2076. [PubMed: 18060892]

8. Drewnowski A, Specter SE. Poverty and obesity: the role of energy density and energy costs. Am J Clin Nutr. 2004; 79(1):6-16. [PubMed: 14684391] 
9. Drewnowski A, Darmon N. Food choices and diet costs: an economic analysis. J Nutr. 2005; 135(4):900-904. [PubMed: 15795456]

10. Widome R, Neumark-Sztainer D, Hannan PJ, Haines J, Story M. Eating when there is not enough to eat: eating behaviors and perceptions of food among food-insecure youths. Am J Public Health. 2009; 99(5):822-828. [PubMed: 19299675]

11. Gucciardi E, Vogt JA, DeMelo M, Stewart DE. Exploration of the relationship between household food insecurity and diabetes in Canada. Diabetes Care. 2009; 32(12):2218-2224. [PubMed: 19720843]

12. Cook JT, Frank DA. Food security, poverty, and human development in the United States. Ann NY Acad Sci. 2008; 1136:193-209. [PubMed: 17954670]

13. Bisgaier J, Rhodes KV. Cumulative adverse financial circumstances: associations with patient health status and behaviors. Health Soc Work. 2011; 36(2):129-137. [PubMed: 21661302]

14. Belsky DW, Moffitt TE, Arseneault L, Melchior M, Caspi A. Context and sequelae of food insecurity in children's development. Am J Epidemiol. 2010; 172 (7):809-818. [PubMed: 20716700]

15. Kirkpatrick SI, McIntyre L, Potestio ML. Child hunger and long-term adverse consequences for health. Arch Pediatr Adolesc Med. 2010; 164(8):754-762. [PubMed: 20679167]

16. Larson NI, Story MT. Food insecurity and weight status among U.S. children and families: a review of the literature. Am J Prev Med. 2011; 40(2):166-173. [PubMed: 21238865]

17. Jones SJ, Frongillo EA. Food insecurity and subsequent weight gain in women. Public Health Nutr. 2007; 10(2):145-151. [PubMed: 17261223]

18. Basiotis, PP.; Lino, M. Nutrition Insight. Vol. 26. Alexandria, VA: US Department of Agriculture, Center for Nutrition Policy and Promotion; 2002. Food insufficiency and prevalence of overweight among adult women. Available at: http://www.cnpp.usda.gov/Publications/NutritionInsights/Insight26.pdf

19. Townsend MS, Peerson J, Love B, Achterberg C, Murphy SP. Food insecurity is positively related to overweight in women. J Nutr. 2001; 131(6):1738-1745. [PubMed: 11385061]

20. Scheier LM. What is the hunger-obesity paradox? J Am Diet Assoc. 2005; 105(6):883-884. 886. [PubMed: 15942535]

21. Crawford PB, Webb KL. Unraveling the paradox of concurrent food insecurity and obesity. Am J Prev Med. 2011; 40(2):274-275. [PubMed: 21238879]

22. Wilde PE, Peterman JN. Individual weight change is associated with household food security status. J Nutr. 2006; 136(5):1395-1400. [PubMed: 16614436]

23. Dammann KW, Smith C. Factors affecting low-income women's food choices and the perceived impact of dietary intake and socioeconomic status on their health and weight. J Nutr Educ Behav. 2009; 41(4):242-253. [PubMed: 19508929]

24. McIntyre L, Glanville NT, Raine KD, Dayle JB, Anderson B, Battaglia N. Do low-income lone mothers compromise their nutrition to feed their children? CMAJ. 2003; 168(6):686-691. [PubMed: 12642423]

25. Chilton M, Black MM, Berkowitz C, et al. Food insecurity and risk of poor health among US-born children of immigrants. Am J Public Health. 2009; 99 (3):556-562. [PubMed: 19106417]

26. Robert SA, Reither EN. A multilevel analysis of race, community disadvantage, and body mass index among adults in the US. Soc Sci Med. 2004; 59(12):2421-2434. [PubMed: 15474198]

27. Sánchez-Vaznaugh EV, Kawachi I, Subramanian SV, Sánchez BN, Acevedo-Garcia D. Do socioeconomic gradients in body mass index vary by race/ethnicity, gender, and birthplace? Am J Epidemiol. 2009; 169(9):1102-1112. [PubMed: 19299405]

28. Blumberg SJ, Bialostosky K, Hamilton WL, Briefel RR. The effectiveness of a short form of the household food security scale. Am J Public Health. 1999; 89 (8):1231-1234. [PubMed: 10432912]

29. US Department of Agriculture. [Accessed May 12, 2011] US Household Food Insecurity Module: Three Stage Design With Screeners. 2008. Available at: http://www.ers.usda.gov/briefing/foodsecurity/surveytools/hh2008.pdf

30. National Heart, Lung, and Blood Institute. [Accessed May 12, 2011] Clinical Guidelines on the Identification, Evaluation, and Treatment of Overweight and Obesity in Adults. 1998. Available at: http://www.nhlbi.nih.gov/guidelines/obesity/ob_home.htm 
31. Yanovski SZ. Binge eating disorder: current knowledge and future directions. Obes Res. 1993; 1(4):306-324. [PubMed: 16350580]

32. Story M, Sherwood NE, Himes JH, et al. An after-school obesity prevention program for AfricanAmerican girls: the Minnesota GEMS pilot study. Ethn Dis. 2003; 13 (1 suppl 1):S54-S64. [PubMed: 12713211]

33. Demo DH, Acock AC. Family diversity and the division of domestic labor: how much have things really changed? Fam Relat. 1993; 42(3):323-331.

34. Campbell KJ, Crawford DA, Salmon J, Carver A, Garnett SP, Baur LA. Associations between the home food environment and obesity-promoting eating behaviors in adolescence. Obesity (Silver Spring). 2007; 15 (3):719-730. [PubMed: 17372323]

35. Margolis DJ, Bilker W, Boston R, Localio R, Berlin JA. Statistical characteristics of area under the receiver operating characteristic curve for a simple prognostic model using traditional and bootstrapped approaches. J Clin Epidemiol. 2002; 55(5):518-524. [PubMed: 12007556]

36. Whitaker RC, Phillips SM, Orzol SM. Food insecurity and the risks of depression and anxiety in mothers and behavior problems in their preschool-aged children. Pediatrics. 2006; 118(3):e859e868. [PubMed: 16950971]

37. Isanaka S, Mora-Plazas M, Lopez-Arana S, Baylin A, Villamor E. Food insecurity is highly prevalent and predicts underweight but not overweight in adults and school children from Bogotá, Colombia. J Nutr. 2007; 137(12):2747-2755. [PubMed: 18029494]

38. McIntyre L, Rondeau K, Kirkpatrick S, Hatfield J, Islam KS, Huda SN. Food provisioning experiences of ultra poor female heads of household living in Bangladesh. Soc Sci Med. 2011; 72(6):969-976. [PubMed: 21345564]

39. Bhattacharya J, Currie J, Haider S. Poverty, food insecurity, and nutritional outcomes in children and adults. J Health Econ. 2004; 23(4):839-862. [PubMed: 15587700]

40. Drewnowski A. Obesity, diets, and social inequalities. Nutr Rev. 2009; 67(suppl 1):S36-S39. [PubMed: 19453676]

41. Nord, M. Workshop on Understanding the Relationship Between Food Insecurity and Obesity. Institute of Medicine; Nov. 2010 Available at: http://www.iom.edu/ /media/Files/Activity\%20Files/Nutrition/FoodInsecurityandObesity/ Nord.pdf

42. Mead MN. The sprawl of food deserts. Environ Health Perspect. 2008; 116(8):A335. [PubMed: 18709173]

43. Andreyeva T, Blumenthal DM, Schwartz MB, Long MW, Brownell KD. Availability and prices of foods across stores and neighborhoods: the case of New Haven, Connecticut. Health Aff (Millwood). 2008; 27(5):1381-1388. [PubMed: 18780928]

44. Lucan SC, Karpyn A, Sherman S. Storing empty calories and chronic disease risk: snack-food products, nutritive content, and manufacturers in Philadelphia corner stores. J Urban Health. 2010; 87(3):394-409. [PubMed: 20405225]

45. Walker RE, Keane CR, Burke JG. Disparities and access to healthy food in the United States: a review of food deserts literature. Health Place. 2010; 16(5):876-884. [PubMed: 20462784]

46. Song HJ, Gittelsohn J, Kim M, Suratkar S, Sharma S, Anliker J. Korean American storeowners' perceived barriers and motivators for implementing a corner store-based program. Health Promot Pract. 2011; 12(3):472-482. [PubMed: 20424001]

47. Dong, D.; Leibtag, E. Promoting Fruit and Vegetable Consumption: Are Coupons More Effective Than Pure Price Discounts?. US Department of Agriculture Economic Research Service; 2010. Available at: http://www.ers.usda.gov/Publications/ERR96/ERR96.pdf

48. Castner, L.; Henke, J. Benefit Redemption Patterns in the Supplemental Nutrition Assistance Program. Food and Nutrition Service, US Department of Agriculture; 2011. Available at: http://www.fns.usda.gov/ora/MENU/Published/snap/FILES/ProgramOperations/ ARRASpendingPatterns.pdf

49. Olson CM, Bove CF, Miller EO. Growing up poor: long-term implications for eating patterns and body weight. Appetite. 2007; 49(1):198-207. [PubMed: 17442454]

50. Keenan DP, Olson C, Hersey JC, Parmer SM. Measures of food insecurity/security. J Nutr Educ. 2001; 33(suppl 1):S49-S58. [PubMed: 12857544] 
TABLE 1

Food Security Status by Sociodemographic Characteristics of Project F-EAT Parents $(n=2095)$ : Minneapolis-St. Paul, Minnesota, 2009-2010

\begin{tabular}{|c|c|c|c|}
\hline Characteristics & $\begin{array}{l}\text { Food-Secure Parents }(n=1279), \% \\
\text { (No.) }\end{array}$ & $\begin{array}{l}\text { Food-Insecure Parents }(\mathrm{n}=\mathbf{8 1 6}) \\
\%(\text { No.) }\end{array}$ & $P$ \\
\hline Gender & & & .025 \\
\hline Female & $60.4(1169)$ & $39.6(768)$ & \\
\hline Male & $69.4(109)$ & $30.6(48)$ & \\
\hline Race/ethnicity & & & $<.001$ \\
\hline White & $70.9(436)$ & $29.1(179)$ & \\
\hline Black or African American & $61.8(360)$ & $38.2(223)$ & \\
\hline Hispanic or Latino & $63.3(224)$ & $36.7(130)$ & \\
\hline Asian American & $47.4(185)$ & $52.6(205)$ & \\
\hline Native American & $50.0(28)$ & $50.0(28)$ & \\
\hline Mixed or other & $42.6(26)$ & $57.4(35)$ & \\
\hline Marital status & & & $<.001$ \\
\hline Married & $66.3(844)$ & $33.7(430)$ & \\
\hline Single & $53.2(430)$ & $46.8(378)$ & \\
\hline Education & & & $<.001$ \\
\hline Did not finish high school & $52.5(324)$ & $47.5(293)$ & \\
\hline Finished high school & $62.1(273)$ & $37.9(167)$ & \\
\hline Some college & $56.3(316)$ & $43.7(245)$ & \\
\hline Finished college & $74.3(248)$ & $25.7(86)$ & \\
\hline Advanced degree & $89.3(109)$ & $10.7(13)$ & \\
\hline Highest household education & & & $<.001$ \\
\hline Did not finish high school & $51.0(235)$ & $49.0(226)$ & \\
\hline Finished high school & $58.1(266)$ & $41.9(192)$ & \\
\hline Some college & $54.9(328)$ & $45.1(269)$ & \\
\hline Finished college & $72.4(267)$ & $27.6(102)$ & \\
\hline Advanced degree & $90.3(177)$ & $9.7(19)$ & \\
\hline Employment status & & & $<.001$ \\
\hline Working full time & $69.0(668)$ & $31.0(300)$ & \\
\hline Working part time & $64.9(226)$ & $35.1(122)$ & \\
\hline Stay at home caregiver & $50.2(142)$ & $49.8(141)$ & \\
\hline Currently unemployed but actively seeking work & $45.1(96)$ & $54.9(117)$ & \\
\hline Not working for pay & $52.8(131)$ & $47.2(117)$ & \\
\hline Household income, \$ & & & $<.001$ \\
\hline$<20000$ & $44.6(335)$ & $55.4(417)$ & \\
\hline $20000-34999$ & $56.1(257)$ & $43.9(201)$ & \\
\hline $35000-49999$ & $65.3(203)$ & $34.7(108)$ & \\
\hline $50000-74999$ & $80.4(189)$ & $19.6(46)$ & \\
\hline$\geq 75000$ & $93.8(242)$ & $6.2(16)$ & \\
\hline
\end{tabular}


TABLE 2

Unadjusted Differences in Parental Characteristics by Food Security Status Among Project F-EAT Parents (n = 2095): Minneapolis-St. Paul, Minnesota, 2009-2010

\begin{tabular}{|c|c|c|c|}
\hline Characteristics & $\begin{array}{c}\text { Food-Secure Parents }(n=1279) \\
\text { Mean } \pm \text { SD or } \%(\text { No. })\end{array}$ & $\begin{array}{c}\text { Food-Insecure Parents }(n=816), \\
\text { Mean } \pm \text { SD or } \%(\text { No. })\end{array}$ & $\boldsymbol{P}$ \\
\hline Body mass index & $28.0 \pm 6.0$ & $29.3 \pm 6.6$ & $<.001$ \\
\hline Overweight or obese status & $64.7(782)$ & $72.5(551)$ & $<.001$ \\
\hline Obese status & $29.4(355)$ & $38.4(292)$ & $<.001$ \\
\hline \multicolumn{4}{|l|}{ Eating patterns } \\
\hline Breakfast consumption, times/wk & $4.7 \pm 2.5$ & $4.0 \pm 2.6$ & $<.001$ \\
\hline Servings of fruits and vegetables, servings/d & $3.8 \pm 2.0$ & $3.5 \pm 2.0$ & $<.001$ \\
\hline Sugar-sweetened beverages, drinks/d & $2.9 \pm 4.1$ & $4.0 \pm 4.6$ & $<.001$ \\
\hline Fast food consumption, times/wk & $1.2 \pm 1.2$ & $1.3 \pm 1.3$ & .013 \\
\hline Binge eating & $6.4(81)$ & $11.3(91)$ & $<.001$ \\
\hline \multicolumn{4}{|c|}{ Home food environmental factors } \\
\hline Family meal frequency, times/wk & $4.7 \pm 1.4$ & $4.7 \pm 1.4$ & .93 \\
\hline Fast food at family meals, times/wk & $0.8 \pm 0.9$ & $1.0 \pm 0.9$ & .004 \\
\hline \multicolumn{4}{|l|}{ Foods served at family meals } \\
\hline Green salad & $30.4(372)$ & $24.7(191)$ & .006 \\
\hline Vegetables & $72.0(878)$ & $63.7(489)$ & $<.001$ \\
\hline Fruit & $34.7(421)$ & 29.9 (229) & .026 \\
\hline $100 \%$ juice & $28.9(352)$ & $30.1(231)$ & .57 \\
\hline Milk & $55.6(673)$ & $50.0(376)$ & .004 \\
\hline Sugar-sweetened beverages & $18.5(226)$ & $26.7(206)$ & $<.001$ \\
\hline Time spent preparing meals (hrs/wk) & $9.2 \pm 6.9$ & $10.7 \pm 8.2$ & $<.001$ \\
\hline \multicolumn{4}{|l|}{ Perceived fruit/vegetable access } \\
\hline Fruits too expensive & $13.8(175)$ & $40.6(326)$ & $<.001$ \\
\hline Vegetables too expensive & $6.4(81)$ & $25.0(201)$ & $<.001$ \\
\hline Limited variety & $13.5(171)$ & $25.7(207)$ & $<.001$ \\
\hline Poor quality & $7.3(93)$ & $19.4(156)$ & $<.001$ \\
\hline
\end{tabular}




\section{TABLE 3}

Differences in Adjusted by Food Security Status Among Project F-EAT Parents ( $\mathrm{n}=2095)$ : Minneapolis-St. Paul, Minnesota, 2009-2010

\begin{tabular}{|c|c|c|c|}
\hline Characteristics & $\begin{array}{l}\text { Food-Secure Parents }(n= \\
\text { 1279) }\end{array}$ & $\begin{array}{l}\text { Food-Insecure Parents }(n= \\
\text { 816) }\end{array}$ & Adjusted Difference \\
\hline Adjusted body mass index, mean $(95 \% \mathrm{CI})$ & $28.2(27.8,28.6)$ & $29.1(28.7,29.6)$ & $0.9^{* *}(0.3,1.5)$ \\
\hline Overweight or obese status, $\%(95 \%$ CI) & $66.3(63.3,69.1)$ & $73.0(69.4,76.4)$ & $6.7^{* *}(1.9,11.1)$ \\
\hline Obese status, \% (95\% CI) & $29.2(26.5,32.1)$ & $36.9(33.2,40.8)$ & $7.7^{* *}(2.6,12.2)$ \\
\hline \multicolumn{4}{|l|}{ Adjusted eating patterns, mean $(95 \% \mathrm{CI})$} \\
\hline Breakfast consumption, times/wk & $4.6(4.4,4.7)$ & $4.2(4.0,4.4)$ & $-0.4^{* *}(-0.5,-0.1)$ \\
\hline Servings of fruits and vegetables, servings/d & $3.8(3.7,3.9)$ & $3.5(3.3,3.6)$ & $-0.3^{* *}(-0.5,-0.1)$ \\
\hline Sugar-sweetened beverages, drinks/d & $3.0(2.7,3.2)$ & $3.8(3.5,4.1)$ & $0.8^{* *}(0.4,1.2)$ \\
\hline Fast food consumption, times/wk & $1.2(1.1,1.3)$ & $1.3(1.2,1.4)$ & $0.1^{*}(0.1,0.3)$ \\
\hline Binge eating & $6.3(5.0,7.8)$ & $11.1(8.9,13.7)$ & $4.8^{* *}(2.1,7.7)$ \\
\hline \multicolumn{4}{|c|}{ Adjusted home food environment factors, mean } \\
\hline Family meal frequency, times/wk (95\% CI) & $4.6(4.6,4.7)$ & $4.7(4.6,4.8)$ & $0.1(-0.1,0.2)$ \\
\hline Fast food at family meals, times/wk (95\% CI) & $0.9(0.8,0.9)$ & $1.0(0.9,1.0)$ & $0.1^{* *}(0.1,0.2)$ \\
\hline \multicolumn{4}{|l|}{ Foods served at family meals, $\%(95 \% \mathrm{CI})$} \\
\hline Green salad & $29.6(27.0,32.5)$ & $24.6(21.4,28.0)$ & $-5.0 *(-9.3,-0.1)$ \\
\hline Vegetables & $72.3(69.4,75.0)$ & $66.4(62.5,70.0)$ & $-5.9^{*}(-10.0,-0.1)$ \\
\hline Fruit & $34.8(32.0,37.8)$ & $28.9(25.5,32.5)$ & $-5.9^{*}(-10.4,-1.3)$ \\
\hline $100 \%$ juice & $28.1(25.5,30.9)$ & $28.8(25.5,32.4)$ & $0.7(-3.6,5.0)$ \\
\hline Milk & $55.1(51.9,58.3)$ & $52.7(48.7,56.8)$ & $-2.4(-6.6,2.4)$ \\
\hline Sugar-sweetened beverages & $15.7(13.5,18.2)$ & $22.0(18.8,25.6)$ & $6.4^{* *}(2.5,10.3)$ \\
\hline Time spent preparing meals, hrs/wk, mean $(95 \% \mathrm{CI})$ & $9.6(9.2,10.0)$ & $10.2(9.7,10.7)$ & $0.6(-0.1,1.3)$ \\
\hline \multicolumn{4}{|l|}{ Perceived fruits and vegetables access, $\%(95 \% \mathrm{CI})$} \\
\hline Fruits too expensive & $13.6(11.8,15.8)$ & $39.8(36.1,43.6)$ & $26.2^{* *}(21.5,30.6)$ \\
\hline Vegetables too expensive & $5.9(4.6,7.4)$ & $24.0(20.7,27.5)$ & $18.1^{* *}(14.9,22.2)$ \\
\hline Limited quality & $12.6(10.8,14.7)$ & $22.0(19.0,25.4)$ & $9.4^{* *}(5.9,13.2)$ \\
\hline Poor quality & $7.3(5.9,8.9)$ & $16.8(14.1,19.9)$ & $9.5^{* *}(6.7,13.1)$ \\
\hline
\end{tabular}

Note. $\mathrm{CI}=$ confidence interval. Differences adjusted for age, gender, race/ethnicity, marital status, employment status, and highest household education.

${ }^{*} P<.05$

*** $P<.01$. 